Original Article 
Family demography and income inequality in West Germany and the United States

Hannah Zagel

Postdoctoral Researcher

Humboldt-University Berlin

Faculty of Humanities and Social Sciences

Department of Social Sciences

Unter den Linden 6

10099 Berlin

Germany

and

WZB Berlin Social Science Center

Demography and Inequality Research Group

Reichpietschufer 50

10785 Berlin

Germany

Phone: +49 3020934447

Email: hannah.zagel@hu-berlin.de

Richard Breen

Professor of Sociology

University of Oxford

Nuffield College

1 New Road

Oxford

OX1 1NF

United Kingdom

Phone: +44 1865278500

Email: richard.breen@nuffield.ox.ac.uk 


\section{Authors' short bios}

Hannah Zagel is a Postdoctoral Researcher at the Department of Social Sciences at Humboldt-University of Berlin and a member of the Demography and Inequality research group at WZB Berlin Social Science Center. She obtained her PhD from the University of Edinburgh in 2013 and held postdoc positions at the University of Bremen and the University of Hamburg. Her research interests include family demography, social inequalities and social policy.

Richard Breen is Professor of Sociology at Oxford University and a Fellow of Nuffield College. Previously, he was the William Graham Sumner Professor of Sociology and the Chair of the Sociology Department at Yale University, where he also directed the Center for Research on Inequalities and the Life Course. He has been an Official Fellow of Nuffield College (2001-2006), and Professor of Sociology at the European University Institute (19972001) and at Queen's University, Belfast (1991-97). He is a Fellow of the British Academy, a Member of the Royal Irish Academy and a Member of the Academia Europaea. 


\title{
Family demography and income inequality in West Germany and the United States
}

Hannah Zagel ${ }^{1}$ and Richard Breen ${ }^{2}$

\begin{abstract}
Income inequality has grown in many countries over the past decades. Single country studies have investigated how trends in family demography, such as rising female employment, assortative mating and single parenthood, have affected this development. But the combined effects have not been studied sufficiently, much less in a comparative perspective. We apply decomposition and counterfactual analyses to Luxembourg Income Study data from the 1990s and 2000s for West Germany and the US. We counterfactually analyse how changes in the distribution of men's and women's education, employment and children across households between the 1990s and 2000s affected overall inequality (Theil index). We find that changes in family demography between the 1990s and the 2000s explain inequality growth in West Germany but not in the US, where the effects of gendered changes in education and employment offset each other. In West Germany, changes in the distribution of household types, and particularly changes in men's employment and education, contributed to increases in income inequality. The country differences in the relationship between changes in family demography and inequality growth reflect how the decline in men's and the growth in women's employment played out differently in the weakening male breadwinner context in West Germany and in the universal breadwinner context in the US.
\end{abstract}

\section{Keywords}

Family demography, income inequality, decomposition, counterfactual analysis, Germany, United States

\section{Acknowledgements}

This project was supported by a fellowship as part of the Postdoc Programme of the German Academic Exchange Service (DAAD). We would like to thank the reviewers and the editors for their constructive comments on the paper.

\footnotetext{
${ }^{1}$ Humboldt-University of Berlin and WZB Berlin Social Science Center, Berlin, Germany ${ }^{2}$ University of Oxford and Nuffield College, Oxford, UK

Corresponding Author: Hannah Zagel, Department of Social Sciences, HumboldtUniversity, Unter den Linden 6, 10099 Berlin, Germany. Email: hannah.zagel@hu-berlin.de
} 


\section{Introduction}

Over the past decades, there have been great changes in patterns of partnership and family formation as well as in the distribution of market work between men and women. Within a given society, the income distribution is influenced by developments in market and institutional factors (Atkinson, 2003) and by demographic changes (McCall and Percheski, 2010). The literature relating household composition to inequality has focused on three key themes: changes in the number of households headed by a single person with dependents, changes in the prevalence of households headed by two earners, and changes in educational homogamy in couples (Breen and Andersen, 2012). The latter two are interrelated, and both are associated with women's increased labour market participation (Nieuwenhuis et al. 2017).

These family demographic trends contribute to shaping differences in income distributions over time and between countries (Martin, 2006; OECD, 2011; Gornick and Jäntti, 2013) and are often believed to affect the continuing growth in income inequality across rich postindustrial countries. For example, growth in the number of dual-income households increases the share of high-income households. Increased socioeconomic homogamy is thought to escalate the effect of increasing numbers of dual-earner households, as women and men with high market power combine their resources. Further, the growing number of single-parent households affects inequality by boosting the share of low-income households. These relationships are also key to the 'diverging destinies' thesis (McLanahan, 2004), which argues that inequality widens due to a polarization in lower-educated and higher-educated mothers' family formation behaviour.

Although the lack of comparability in study design makes it difficult to draw strong quantitative conclusions, existing evidence shows that the growth in the share of single mother households is the only consistent contributor to growing inequality (Kollmeyer, 2013). If they have any effect at all, overall increases in women's employment have been found to ameliorate inequality (Bradley et al., 2003). There is mixed evidence for effects on inequality of educational matching among partners in couples. While partners' growing educational similarity is rarely found to contribute to increasing inequality (Breen and Salazar, 2011; Western et al., 2008), rising earnings similarity seems to have had an effect (Burtless, 1999; Schwartz, 2010). In addition, Nieuwenhuis et al. (2017) have demonstrated the importance of changes in women's earnings inequality for trends in overall income inequality. In countries where inequality in women's earnings decreased, this tended to attenuate increases in overall inequality among couples. 
Despite the wealth of research in this area, a few gaps remain. First, although there are good reasons for focusing on the substantial changes in women's market position over the past decades, it is striking that changes in men's education and employment have been looked at less often. Research has rarely tested whether changes among men have had a separate effect on inequality growth. It does not seem sufficient to only look at men in the couple context (earnings correlations or relative income contributions) given that men's earnings disparities remain the main driver in overall household earnings inequality (OECD, 2011). Second, in light of the notable increases in the share of one-person households across rich countries (Jamieson and Simpson, 2013), it is vital to consider such households alongside couples in order to understand the links between family demography and inequality. Third, the majority of studies have either aimed to describe the links between family demography and inequality in a single country context (mostly in the US) over time or to test whether the relationships may be generalized in a multi-country setting. These studies have considerably broadened our understanding of the links between demography and inequality. However, a shorter time period and a smaller number of countries should facilitate a deeper understanding of how the trends are shaped by particular historical time periods and national contexts. Multi-country time series analyses typically allow little space for contextualizing the findings.

The main contribution of the present paper is that it compares two countries with distinct institutional settings and characteristic gendered household arrangements in a selected time period. We compare West Germany ${ }^{1}$, a country with a prevailing strong male breadwinner norm (Daly, 2000) and the US, which has a universal breadwinner model (Sainsbury, 1999). Both of these countries have seen a continuous rise in income inequality, albeit on different levels. We focus on the 1990s to the 2000s, a period in which demographic changes had levelled off and the financial crisis was yet to take effect. This allows us to better isolate the relationships between context, demography and inequality. We address two research questions. First, how did changes in family demography contribute to the growth in income inequality in Germany and the US throughout the 1990s and 2000s? Specifically, we look at changes in the distribution of men's and women's education, the distribution of men's and women's employment and the distribution of children across households. Second, what is the contribution of changes in female-headed one-person households with different levels of market power for the growth in oncome inequality in the two countries in this period?

The study design allows us to investigate whether trends that are often implicitly assumed to be universal - for instance, those invoked in the diverging destinies thesis - play out differently in contexts with distinct gendered work arrangements. We expect women's 
improved market power to have a less equalizing effect on inequality in Germany’s one-anda-half earner context than in the US. We also expect changes in men's labour market position to be better cushioned in the US dual-earner context than in Germany, and the contribution of growth in female-headed one-person households with low market position to inequality to be high in both contexts. In order to test these expectations, the paper applies decomposition and counterfactual analyses on harmonized data from the Luxembourg Income Study (LIS). Our results indicate that changes in men's and women's education and employment have indeed pulled into different directions regarding their effects on income inequality.

\section{Family demography and income inequality}

The role played by changes in family demography for the growth of inequality has been comprehensively studied. As noted above, two of the main trends discussed in this literature are increases in the share of dual-earner households on the one hand and of single parent households on the other. While the driving force behind the first trend is changes in women's market position, the second trend arguably results from an interrelation between changes both in female employment and in union- and family-formation patterns. This section reviews the current research and identifies some gaps.

Research on the role of changes in women's market position has mostly looked at heterosexual couple households (Nieuwenhuis et al., 2017: 16), thus omitting single parent and one-person households. Nieuwenhuis et al. (2017) have identified three mechanisms based on a sample of 18 OECD countries: (1) the increasing correlations between spouses' earnings have intensified inequality, but (2) the reduction of inequality in women's earnings and (3) rising shares of women's earnings to the total household income have contributed to decreases in inequality since the 1970s. Other studies found that the increasing labour force participation of wives either reduced or had no effect on inequality (Harkness, 2013, 2013; Pasqua, 2008). Growing educational assortative mating appears to have had no effect on inequality in the US (Breen and Salazar, 2011; Western, Bloome and Percheski, 2008) whereas sorting on earnings or income seems to have contributed to its growth (Burtless, 1999; Schwartz, 2010). In Germany, household earnings inequality increased between 1984 and 2004, partly due to a growing share of employed individuals with a spouse in the same earnings quintile (OECD, 2011). Breen and Salazar (2011: 830-3) have pointed out that, as greater similarity in earnings among couples is not explained by the changes in their sorting on education, it must be due to other factors, such as couples' employment decisions. 
The growing prevalence of single motherhood is one of the most typically cited indicators for change in family demography (Cherlin, 2010), but the focus is often on the US. It can affect income inequality by increasing the share of low-income households. Pronounced shifts in divorce and remarriage happened in the period after the end of the Second World War in the US (Teachman et al., 2000). During the 1990s and 2000s, a polarization in family patterns by education and income became increasingly obvious. This was characterized by family stability among the highest-educated group and instability among the lowest-educated one (Cherlin, 2010). In this context, McLanahan (2004) highlighted the risk of 'diverging destinies' with respect to the consolidating differences in children's life chances depending on their social origin. Hence, changes in women's market position and increases in single motherhood can be seen as interrelated causes for inequality growth. Accordingly, in a multicountry trend design, Kollmeyer (2013) found that female employment, homogamy in couple's education and single motherhood affect income inequality separately and in the expected directions. The study also shows that the share of single mothers in a country (increasing inequality) confounds the effect of higher shares of female labour market participation (reducing inequality). This means that the inequality-reducing effect of female employment is stronger once the share of single mother households is controlled for, because single mothers have often depended on joining the workforce, but their incomes are comparatively low (Nieuwenhuis and Maldonaldo, 2018).

In addition to the trends discussed above, another marked demographic shift since the 1970s is the increase in the share of persons with no partner and no children in the household (Jamieson and Simpson, 2013; Jalovaara and Fasang, 2017). The relationship of this shift with income inequality is much less examined in the literature. The 1990s and 2000s saw a particular surge in one-person households in younger age groups in their 20s and 30s (Chandler et al., 2004; Ronald, 2017). Growth in the prevalence of one-person households generally reduces countries' average household sizes (OECD, 2011) and thus reduces the share of households in which individual incomes of partners are pooled. However, the way the development plays out for income inequality depends on the relative market power of the one-person households. As the result of population ageing, growing shares of households consisting of low-income older people living alone could mean increasing inequality. In general, women in one-person households are at a greater disadvantage than men (Quintano and D’Augustino, 2006). Indeed, there is evidence showing that the growth in single-headed households increased income inequality in Germany, but previous studies did not account for gender (Peichl et al., 2012) or omitted employment (Spitzenpfeil and Andreß, 2014). 
Taken together, these are three aspects of the links between demography and inequality that require further investigation. First, US exceptionalism should be put to the test, because the social gradient in family formation in the US is stronger and welfare provision is less generous than in European countries. Here, more in-depth country comparisons with single countries will shed more light on contextual influences than multi-country comparisons, which aim at generalization. Second, the period from the 1990s should be considered more closely, because inequality among families seems to have increased and the demographic profile of one-person households has changed. Third, with previous research suggesting that demographic changes do not have a uniform impact on income inequality, it is important to consider the trends together to separate out the correlated effects (Western et al., 2008). For example, this would allow us to see whether female employment offsets the effect of the growing share of single parent households or whether changes in women's education do not have an impact because men’s labour market participation has also changed.

\section{Comparative framework and expectations}

In this study, we focus on West Germany and the US. In both countries, income inequality continuously increased, and similar family demographic trends unfolded during the 1990s and 2000s, albeit on different levels. There was also a strong and well-documented trend towards convergence in women's and men's market positions in both contexts in this period. On the one hand, women's and men's education became more similar, with decreases at the low attainment level for both men and women but increases at the top for women (Mandel and Semyonov, 2014; Spitzenpfeil and Andreß, 2014). On the other hand, while overall employment further increased for women, it decreased for men (Sacher, 2005; White and Rogers, 2000). This latter shift was related to women's growing entry into professional and managerial jobs (Busch, 2013; England, 2005) and a rising number of low-skilled men losing their jobs (Oesch, 2010; Wolcott, 2017). These changes are also reflected in trends in gender wage gaps, which have consistently declined in the two countries since the early 1990s (OECD, 2017). Yet despite the similarities, the different institutionalized breadwinner models are likely to have affected men's and women's relative contributions to household incomes differently and thus the overall distribution of incomes across households.

The breadwinner models in the US and West Germany are supported by tax systems and family policies that set different incentive structures for women's and men’s labour market participation (Aisenbrey et al., 2009). This is especially relevant for couples’ work arrangements but also affects the labour market positions of singles, for example, separated or 
divorced individuals (Giddings et al., 2004). By the 1980s, the US had established a universal breadwinner model (Sainsbury, 1999). Not least due to the lack of family-oriented policy measures, dual-earning had become common, and both women's and men's full-time wages often contributed to the household income. Part-time employment is not a supported arrangement (Blau and Kahn, 2013).

In West Germany, the male breadwinner model remained firmly in place throughout the century, but it weakened from the 1980s onwards, with growing numbers of women entering the labour force. However, rather than a dual-earner model, a one-and-a-half earner arrangement emerged (Daly, 2011). Germany’s strong labour market regulation and generous social security system mean that there are comparatively small wage penalties for part-time compared to full-time employment (McGinnity and McManus, 2007). This makes part-time employment attractive in Germany. The option is particularly used by women and was further supported by the introduction of the legal right to work part time in 1999.

Consequently, despite continuing increases in the 1990s, women's contribution to household earnings has remained lower in Germany than in the US (Nieuwenhuis et al., 2017). We thus expect changes in women's education and employment to have had a less equalizing effect on inequality in Germany than in the US. Further, we expect the dual-earner context of the US to have offset the changes in men’s education and employment, which affected their relative position compared to women negatively, better than in Germany. Lastly, any increase in inequality that is due to increases in female-headed one-person households should be more pronounced if the women have a weak market position.

\section{Empirical strategy}

Our analysis focuses on changes in inequality in the distribution of equivalized disposable income among households in Germany and the US between the early 1990s and mid-2000s. We aim to investigate the effects of several aspects of changes in household composition including changes in educational assortative mating, the growth of dual earner households, and changes in family structures, particularly changes in the share of households with children headed by a single person. Accordingly, we adopt a more comprehensive definition of household types than earlier studies. Households are characterized by the highest educational attainment of the household head and spouse (if present), whether or not the head and the spouse (if present) are employed and whether or not the household contains children under the age of 18. This schema allows us to identify a variety of households, for example, households without children but with two highly educated, working adults. Another type would be 
households with a low-educated single woman, who is employed and has a child in the household.

Household types can differ in their average income and in the variation of income among households of that type. Thus, overall income inequality among households can be decomposed into between-household-type and within-household-type components. Betweentype inequality captures the differences in average incomes between the different household types weighted by their relative frequency. Within-group inequality, on the other hand, captures differences in incomes within each household type, weighted by the relative frequency of the type. Changes in family demography will have their largest impact on between-type inequality because they change the distribution of household types, but such changes will also have some effect on within-type inequality, because they change the weighting that each type receives in the calculation. ${ }^{2}$ But whether changes in the distribution of household types leads to increases or declines in overall income inequality depends on which household types become more or less numerous. For example, between-household inequality would rise if household types with higher average incomes or those with lower average incomes became relatively more numerous.

\section{Using LIS data}

We use data from the Luxembourg Income Study (LIS) (LIS, 2013) for our comparative analysis. The data for the US were originally collected in the Current Population Survey (CPS) and for Germany they come from the German Socio-Economic Panel (SOEP) ${ }^{3}$. LIS harmonizes its data sets: each study's income measures are adapted to pre-defined, common concepts. Four waves of data are used for each country, two covering the early-1990s time period (1989 and 1994 for Germany ${ }^{4}$; 1991 and 1994 for the US), and the other two covering the 2000s time period (2004 and 2007 for both countries). We will hence compare income distributions at two cross-sections, each spanning a 4-6 year period (allowing us to average out short term fluctuations in income) and separated by a gap of roughly 12 years. It was in this period that the above-discussed differences in breadwinning and labour market structures between the countries consolidated. We restrict our analysis to working age households by limiting our sample to households in which both the head and spouse/partner (if present) are aged between 25 and $64 .^{5}$

\section{Household income}

We use equivalized disposable household income because it better captures differences in the resources on which families can draw than their earnings in the labour market. We chose this 
income concept to reflect inequality in resources of households after taking government transfers into account. Transfer payments may change the position of a given household in the income distribution, especially considering that eligibility for payments varies with household structure. By using this income concept, we can account for differences in state support for certain households between the two countries we compare. The LIS indicator of disposable household income excludes two non-monetary forms of income, namely that from capital (value of the service of durable goods owned by the household) and that from universal government services directed at meeting the general needs of the overall population rather than those of specific groups (housing, education, health) (LIS, 2013). The latter category includes childcare services, which may be relevant for the present study. True variation in disposable income among households with children may therefore be greater than we can observe. We equivalize by dividing income by the square root of the number of people in the household. This strategy highlights the economies of scale in consumption, assuming stronger sharing of resources within households than other equivalence scales. ${ }^{6}$ Incomes are expressed in 1991 values. $^{7}$ We use an upper income cut-off of ten times the median (as recommended by LIS, 2013).

\section{Household types}

As explained above, we define a set of household types based on five characteristics:

a) The household head's partnership status (partnered/not partnered), defined by heterosexual co-residence, including married and cohabiting couples. Including cohabitors is crucial for avoiding overestimation of demographic shifts because dualearner arrangements are more common among cohabiting than married couples (Martin, 2006). Unpartnered household heads are kept in the sample, because a focus on couples alone is decreasingly informative for overall income inequality, given the growth in single households.

b) Whether there are children under the age of 18 in the household (yes/no).

c) Both head and partner are characterized by their current employment status (employed/not employed). Employment is defined by whether the individual engaged in any employment activity in the survey period (roughly one year), disregarding differences in work hours and in seasonal labour market activity.

d) Individuals are characterized by their level of educational attainment in five categories.

Education information is derived from the country-specific data in the LIS, rather than drawing on the harmonized data (only three levels). The country-specific data allow us to 
construct educational categories that reflect key characteristics of the education systems in the two countries. The categories for Germany are: 1: Basic secondary education (Hauptschule and Realschule diplomas); 2: Secondary education (Hauptschule diploma) and completed vocational training; 3: Secondary education (Realschule diploma) and completed vocational training; 4: Secondary academic (Abitur, Fachabitur), secondary academic plus completed vocational training, higher vocational qualification (Meister) or civil service training qualification; and 5: Higher education degree. The educational attainment levels for the US are: 1: Not completed high school; 2: High school diploma; 3: Some college or associate degree; 4: BA; 5: MA or higher degree.

With 5 categories of educational attainment, there are 10 possible combinations of educational level and employment status for each man and woman. By adding another category for singles that indicates that there is no man (or no woman) in the household, we get $11 \times 11=121$ combinations. Of these 121 combinations, one of them is not possible (both absent). That leaves 120 combinations. When we consider households with and without children, this doubles the possible combinations $(2 \times 120)=240$. Empirically, not all of these combinations are observed. For example, households in which women are in the highest category and men in the lowest are extremely rare. We have observations in 217 (1990s) and 230 (2000s) groups in the German sample and 238 groups in the US sample. ${ }^{8}$

The Theil index, decomposition and counterfactuals

We use the Theil index as a measure of income dispersion. Its chief attraction is its decomposability into within-group and between-group inequality. The Gini coefficient is widely used in studies of income inequality but is less suitable for our purposes because it does not decompose by population subgroups (Cancian and Reed, 1998). Other members of the class of generalized entropy inequality indexes, such as half the squared coefficient of variation (Jäntti, 1997; Peichl, Pestel and Schneider, 2009) and the mean logarithmic deviation, are valid alternatives (Pasqua, 2008: 166). Among these measures, the Theil index is less sensitive to changes at the top (to which half the squared coefficient of variation is more sensitive) and bottom (to which the mean logarithmic deviation is more sensitive) than to changes throughout the income distribution.

The Theil index is written as:

$$
T=\frac{1}{n} \sum_{i=1}^{n} \frac{x_{i}}{\bar{x}} \ln \left(\frac{x_{i}}{\bar{x}}\right)
$$


This defines the average of the ratio of disposable income in an individual household, $x_{i}$, to mean income, $\bar{x}$, multiplied by the log of the same quantity. $n$ denotes the number of households. The index ranges between 0 (when all households have the same income) and $\ln (n)$. The decomposition of the Theil index into between-group and within-group inequality can be written as:

$$
T=\sum_{j} p_{j} \frac{\overline{x_{j}}}{\bar{x}} \ln \left(\frac{\overline{x_{J}}}{\bar{x}}\right)+\sum_{j} p_{j} \frac{\overline{x_{j}}}{\bar{x}} T_{j}
$$

Here, groups (of households) are indexed by $\mathrm{j},\left(\bar{x}_{j}\right)$ is the mean disposable household income in group $j, p_{j}$ is the proportion of households in the jth group, $\bar{x}$, is the overall mean income and $T_{j}$ is the Theil value for income inequality within the $j$ th group. Because we can write $\bar{x}=\sum p_{j} \bar{x}_{j}$, the Theil index depends on just three quantities: $\bar{x}_{j}, p_{j}$ and $T_{j}$. The first part of the equation defines between-group inequality as the logarithm of the ratio of the $j$ th group's mean income to the overall mean. It thus depends on differences in the average earnings of each household type. The second part of the equation measures within-group inequality, where the Theil index is measured for each of the $J$ groups, weighted by the group's population and earnings share and summed over all groups. It depends on the average variation in earnings among households of the same type.

Our analysis proceeds in four steps. First, we compare income inequality and how it changed between the two periods in West Germany and the US, decomposing overall inequality into within-group and between-group inequality. In the second step, we apply a set of basic counterfactuals, where each of the components of the overall Theil index (these are $\bar{x}_{j}, p_{j}$ and $T_{j}$ ) is individually allowed to take its 2000s values while keeping the other components at their 1990s values. With this strategy, we are asking what, hypothetically, would have happened to overall inequality, within-group inequality and between-group inequality if two of the quantities were held constant at their 1990s values and only the third was allowed to take its 2000s value (see Breen and Andersen, 2012: 877 for the same approach). In other words, which of the components is associated with income inequality growth? The next step comprises further counterfactual analyses in which the distribution of household types is decomposed into its single components. Here, we estimate counterfactual inequality by a) only changing the marginal distributions of men's and women's education, b) only changing the marginal distributions of men’s and women's employment, c) only changing the marginal distribution of households with and without children, and d) changing the marginal distribution of men’s and women's employment and education together. In all 
instances, we keep the other quantities at their 1990s values. Fourth, we investigate the role of men's and women's education and employment separately, changing marginal distributions of each to match their distribution in the 2000s while keeping the values of all other components constant. In a final step, following leads from previous research findings, we change the marginal distributions of single household characteristics only.

The results of these simulations should not be interpreted in strictly causal terms (see Altonji et al., 2012 and Breen and Chung, 2015 for the assumptions under which such simulations yield causal estimates). Rather they should be thought of as revealing hypothetical outcomes that would have arisen had the world been different. This allows us to gauge the importance of certain processes for changes in inequality. It should also be noted that our approach does not assume that different demographic trends are uncorrelated.

\section{Findings}

\section{Mapping changes in household structures}

Household composition changed in both countries between the 1990s and 2000s, but in different ways. As Table 1 shows, the share of households headed by a single person without children increased in Germany. The growth of single-headed households was less pronounced in the US. The share of single parent households increased in Germany but changed little in the US. The data suggest that the share of couple households with children dropped in both countries; childless couple households also became less common in Germany though not in the US. ${ }^{9}$

\section{[TABLE 1 ABOUT HERE]}

The distributions of educational attainment (not shown) also changed. In both countries, shares of people with the highest education level increased and shares of people with the lowest level decreased. This is the case for both men and women, but the share of women with the lowest education in West Germany declined more than that of men. Women in Germany saw a large increase in the middle-range category of secondary education: Realschule plus vocational training. In the US, women gained more than men at the top of the educational distribution and the share of women with only a high school diploma shrunk more markedly than that of men. 
Couples are homogamous if both partners have the same level of educational attainment, defined using our 5-category measures. In both countries, aggregate educational homogamy hardly changed between the 1990s and 2000s, with 37\% of couples in Germany and 48\% in the US being educationally homogamous in both periods. Changes over time become apparent only when the different educational levels are considered. The dots in Figure 1 show the proportions of households in each educational combination for Germany and the US; white dots refer to the 1990s and black dots to the 2000s. The single rows in the figure refer to women's education and these are grouped by men's educational level. The top six rows, for example, display the proportions of households according to woman's education for households headed by a single woman (the first row is the empty category, 'no woman in household'). The dots on the 7th to 12th row show the proportions of households in each combination of men's and women's education for which men have the lowest education level. For example, the share of households in which men and women both have basic education decreased from over $3 \%$ to less than $2 \%$ in all household types (8th row from the top) in Germany.

Overall, at the lowest level of education, proportions changed little in the two countries. The graph also shows that, in Germany, households headed by a couple in which either one or both partners have Realschule diplomas and vocational training or higher increased or maintained their 1990s share of the population of households with a few exceptions. The pattern is not apparent in the US, where changes were less pronounced overall. The greatest increases in the US were in the share of couple households where both partners have a BA degree, and in the share of single women with some college or a BA degree. The strongest decrease in the US can be seen in the proportions of couples where both men and women have a high school diploma. In Germany, substantial increases are also apparent for households headed by single men in the top three education levels and households headed by single women at all but the lowest education level.

\section{[FIGURE 1 ABOUT HERE]}

Women's labour market participation by household composition changed between the 1990s and 2000s in both countries. Among single households without children, women's employment dropped slightly in both countries, with around $69 \%$ of women in this household type in employment in the 2000s. Among single parent households, women's employment rose in both Germany and the US. The share of single mothers in employment had been 
comparatively high in Germany (74.4\% of women in a single parent household were employed in the 1990s), so these changes meant a convergence of US levels (from $67.5 \%$ to 74\%) to German levels. Among couple households without children, the share of women in employment increased by 9 percentage points in Germany between the 1990s and 2000s but remained unchanged in the US. Similarly, mothers in couples in Germany have caught up with those in the US, reaching 1990s US levels (71\%), this reflects the changes in the male breadwinner model. The share of working mothers in couples in the US dropped slightly (to $68.6 \%)$.

\section{[FIGURE 2 ABOUT HERE]}

Considering changes in men's employment by education level (Figure 2) overall reveals that the capacity to fulfil the male breadwinner role has been reduced particularly among the lower educated men. The relationship is more obvious in Germany than in the US. Looking at changes in dual-earner couples by their education level (graph not shown), we see a concentration at the top in Germany, which we do not find for the US. In Germany, the largest drops were in proportions of couples with relatively low market positions (both with Hauptschule diploma and vocational training or the man with Hauptschule diploma and vocational training and partner with basic secondary education) and it has increased most among couples with the highest relative market position (both MA or higher). In the US, an increase in dual-earner households was particularly pronounced among homogenous couples where both had a BA degree, and the strongest declines in shares of dual earners occurred among those with high school diplomas.

\section{Changes in inequality}

Median annual disposable equivalized household incomes in $1991^{10}$ increased in Germany (from 14,143 to 16,422 euros) and the US (from \$18,319 to \$20,715). This was true for almost all levels of women's educational attainment in both Germany and the US, with the largest increase in median disposable household incomes among women with a higher education degree. There is greater dispersion of incomes by educational level in the US, as would be expected from the literature. Looking at changes in median incomes by household composition (not shown here), we see further differences between the countries. In Germany, couple households gained more on average than single-headed households. Both couples with and without children saw a growth in median incomes by over 15\%, while single households gained only about $5 \%$. This seems to reflect the growing labour market participation of 
women in couples. But it also reflects the comparatively difficult market position of singleheaded households. The US data presents a rather different picture, with median income gains being much more pronounced among households with children (about 23\% for couples with children and 28\% for single parent households) than among childless households (roughly a 4\% increase among singles, $8 \%$ among couples).

Turning to the changes in overall inequality, the top two rows of Table 2 (Germany) and Table 3 (US) show Theil indices and their between- and within-group components in the 1990s and the 2000s. Inequality in disposable household incomes was much lower in West Germany in both periods. Inequality increased in Germany (by 11\%) and in the US (10\%). The decomposition into between- and within-household-type inequality suggests that the increase in the US was mostly due to growing within-group inequality (increasing by about $13 \%$ compared to a $3 \%$ increase in between-group inequality). This difference is smaller in the German case, where between-group inequality rose about $6 \%$ and within-group inequality by $13 \% .^{11}$

\section{Counterfactual decompositions ${ }^{12}$}

In the first step of our counterfactual decomposition analysis (Panels A of Tables 2 and 3), we ask what would, hypothetically, have happened to overall inequality, within-household-type inequality and between-household type inequality if two of the quantities were held constant at their 1990s values and only the third was allowed to change to its 2000s value. Columns 3 of Tables 2 and 3 give the percentage changes in the overall Theil value since the 1990s for both the observed and the counterfactual values. Only changing the within-group Theil indices for incomes in each household type $\left(T_{j}\right)$ does not (by definition) affect between-group inequality. Change in the within-group Theil value explains a large part of the increase in overall inequality in the US. ${ }^{13}$ For Germany, however, growing within-group inequality appears to have had no effect on inequality. Neither changing the within-group Theil value nor changing the group means results in higher overall inequality. The 'mean incomes' component captures developments in gendered wage gaps or working hours, which are not measured directly. The results suggest that these were associated with a small reduction of inequality in Germany and a small increase in inequality in the US.

\section{[TABLE 2 ABOUT HERE]}

[TABLE 3 ABOUT HERE] 
Changing the proportions of each household type, $\left(p_{j}\right)$ to their 2000s values addresses the main interest of this paper, because it models shifts in household structures while keeping all other factors constant. In the German case doing this leads to increases in the within- and between- components of inequality such that these hypothetical values exceed their observed values for the 2000s. This suggests that change in the distribution of household types was the main source of inequality growth in Germany. For the US, on the other hand, changing the distribution of household types gives a counterfactual inequality less than that observed in the 2000s. The finding is in line with earlier research on earnings inequality, which found that changing partnership patterns did not contribute to increasing inequality in the US (Breen and Salazar, 2011). However, even though this might lead to the conclusion that family change did not affect inequality in the US, it could also mean that different demographic trends balanced each other out. The following steps will investigate this question.

Panels B in Table 2 and Table 3 show the results of the counterfactual decompositions where only one component of $p_{j}$ is changed at a time for each country. We first change the marginal distribution of men's and women's education, including the category where there was no partner, keeping all the other components at their observed 1990s values. For Germany, inequality increases to a level roughly the same as that observed in the 2000s, with both between-group and within-group inequality contributing to that change. In the US, however, overall inequality is reduced to a value slightly lower than that observed in the 1990s. In the next counterfactual (see the second rows in Panels B), only the marginal distribution of men's and women's employment is changed, thereby exploring potential effects of employment independent from education. For Germany, this counterfactual had effects on inequality similar to those of changing the distribution of educational attainment. In the US case, making this change has relatively little effect on inequality. When only the marginal distribution of children across household types was changed, inequality in both countries increased by very little compared to the 1990s, as shown in Rows 3 of Panels B. In the fourth row of Panels B, we counterfactually changed both the marginal distributions of educational attainments and employment. For Germany, this increased the overall Theil value to a level higher than the observed 2000s value, confirming the finding that changes in employment and education together were important in explaining inequality growth. For the US, with this change, overall inequality remained far below the observed 2000s value. ${ }^{14}$

The counterfactuals in Panels $\mathrm{C}$ were aimed at disentangling the separate contributions of changes in men's and women's distributions of education and employment on inequality. As 
discussed above, educational attainment changed for men and women in the two countries, but did so in different ways. Hence, we ask how women's overall higher educational attainments might have affected income inequality if men's attainment had stayed the same as in the 1990s. And here we find a surprising result: this change increased inequality slightly in Germany (the hypothetical Theil value is 0.1306 compared with the observed 1990s Theil value of 0.1279 ) but it changes substantially in the US (0.2308 compared with the 0.2112 observed in the 1990s and 0.2306 in the 2000s). Counterfactually changing the marginal distribution of men's education and keeping the other values at their 1990s levels increased both within-group and between-group inequality in Germany but had little impact in the US. It seems, then, that changes in men's education in Germany, with decreasing shares of men with basic attainments and Hauptschule diploma with vocational training but increases in Realschule graduates with vocational training and higher degrees, led to rising income inequality. We were able to corroborate this finding with a further counterfactual: changing only the distribution of households in which men had a Hauptschule diploma to its 2000s values increased inequality in Germany (Theil= .1321). This finding suggests that the decline in shares of men with the lowest general education contributed to shifts in the income distribution in Germany. In the US, even though the distribution of men's education changed, with increases at the top and decreases at high school diploma and lower (Table 2), this seems to have had little impact on inequality. Here, changes in women's education (growth in academic degrees, decline in high school diploma and below) seem to be associated with rising inequality.

In line with previous research, just changing the employment distribution of women had little effect on inequality in either country. Counterfactually only changing men's employment distribution, however, worked in the opposite direction, causing within-group inequality to increase in Germany and between-group inequality to increase in the US. In additional analyses we learned that the changes in dual-earner-households alone were not the main driver of inequality growth (only changing the distribution of dual-earner households to 2000s values: Germany Theil =.1291, US Theil =.2042). The finding that changing men’s employment had an effect on inequality but changing men's and women's employment together had no effect supports our expectation of balancing trends in men's and women's employment during the 1990s in the US. Each of these changes would have increased inequality by boosting inequality between household types, but they do not do so in combination. In Germany, on the other hand, the association between changes in employment overall and inequality growth seems to be explained partly by changes in men's employment, 
but here changes in the distribution of education also seem to have mattered. Looking at the combined effect of employment and education by gender, we found that changing the marginal distribution of women's education and employment had little or no effect on inequality both in the US and in Germany. However, changing the marginal distribution of men's education and employment together had a strong effect on the Theil value for West Germany by increasing within-group inequality, but affected the Theil value for the US little. This points to a possible additive effect of changes in men's education and employment in Germany, which is only very marginally counteracted by changes in women's employment (but not in education). In addition, investigating our second research question, we found that the growing shares of female-headed one-person households (in Panels D), but only of those where the women were not employed, contributed to the growth in inequality in Germany. This relationship was not found for the US.

In summary, while in the US most of the growth in inequality can be explained by changes in within-group inequality and mean group incomes, changes in the distribution of household types explain more of the increase in income inequality in Germany. Shifts in men's education and employment and increases in the proportion of single households headed by non-working women seem to have been particularly important. The incomes of single nonworking women are especially low compared to the population average, which may be a reason for this household type's particularly strong influence on the income distribution. If we simulate changes in all of these (men's education and employment and households headed by a single non-working woman) together, the Theil value for Germany almost matches its observed 2000s value of 0.1436 , with very similar between-group and within-group inequality. This is strong evidence that these demographic changes drove the increase in inequality in Germany over the period we consider. For the US, on the other hand, we find that the effects of changes in women's education and men's employment on inequality during the 1990s seem to have cancelled each other out.

\section{Conclusions}

In this paper, we report the results of the first comparative study linking changes in income inequality to a comprehensive set of changes in family demography. Unlike most other studies, we include households headed by a single person alongside couple households, and we investigate whether single components of the demographic changes reinforced each other or cancelled each other out. We added to other studies by considering changes in men's education and employment alongside that of women and by using a more detailed educational 
classification and a richer set of demographic characteristics to categorize households. We compared West Germany and the US, focusing on the 1990s and 2000s, to contextualize the relationships between demographic trends and income inequality in the contexts of different breadwinner models.

We find that for Germany, demographic trends indeed seem to play the major a role in the changing distribution of household incomes, while they are of less importance for inequality in the US. Earlier studies of the US have pointed to growing inequality between and especially within household types - rather than any shifts in the distribution of those types as the main reason for the growth of overall inequality. Our analysis supports this argument, but it adds an extra twist. Although demographic changes taken as a whole slightly ameliorated the growth in inequality in the US, certain specific changes did seem to promote inequality, notably the growth in women's education and the change in men's employment. Together, however, these trends seem to have offset each other. We think it is reasonable to assume this mechanism given the universal breadwinner model in the US. The loss of one earner in the household may be better compensated by the other where it is common for both men and women to be employed full time. Investigating these pathways further is a subject for future research.

One challenge for future research is that certain household types are rare in population-level data. In order to strengthen the research by including such data, methodological solutions like the construction of correct bootstrap confidence intervals around decomposition results would be desirable. Further, surveys that oversample rare population subgroups and focus on disadvantaged households with children, like the Fragile Families \& Child Wellbeing Study (Reichman et al., 2001) or the Families in Germany Study (FiD) (Schröder et al., 2013), can be important sources for investigating the links between demography and inequality. Our study contributes to existing research particularly by viewing inequality outcomes of demographic changes in the respective institutional environments. Accordingly, we show that the $10 \%$ increase in inequality between the 1990s and 2000s in the US seems to have occurred in a quite different way than the $11 \%$ increase in West Germany. Most importantly, demographic change, and especially changes in the distribution of educational attainments, contributed to rising income inequality between household types in Germany, as suggested by previous research, even though assortative mating did not emerge as a likely key factor. As expected, changes in employment patterns were important. Counterfactually allowing only the marginal distribution of men's and women's employment to change to its 2000s values 
increased the overall Theil index for Germany by almost 10\%. Our findings also add to previous research showing that changes in the distribution of households with children did not in themselves seem to affect inequality. A further decomposition of household type characteristics by gender revealed that the increase in inequality in Germany was driven by changes in the educational attainment and employment status of men rather than of women. But the increase in single households with non-employed women does seem to have contributed to inequality growth. Taken together, aspects associated with the decline of the male-breadwinner model in West Germany seem to have contributed to rising income inequality between the early 1990s and early 2000s, while in the dual-earner context of the US, gendered changes in family demography have offset each other.

\footnotetext{
${ }^{1}$ We focus on households in the territory of the old Federal Republic of Germany, referred to as West Germany, in this paper, because even decades after unification East Germany features distinct dynamics in family demography. We use ‘Germany' to mean 'West Germany’ throughout the paper.

2 The size of each household type may also affect behavioral changes within groups, which we cannot address in the scope of our analysis.

${ }^{3}$ We treat each wave of the SOEP as an independent cross-section, disregarding the panel structure of the data.
} As we are not conducting inferential statistics, we do not run into the problem of overestimating standard errors by counting some households multiple times.

${ }^{4}$ Residents of regions belonging to the German Democratic Republic until 1990 were dropped from all analyses presented in this article. However, a separate set of analyses showed that the broad outlines of the findings were similar when East Germans were included where possible (for waves 1994, 2004 and 2007).

${ }^{5}$ We use household-level weights (inflated) provided by the LIS in our analyses.

${ }^{6}$ For an overview of the discussion on different equivalence scales see Bennett (2013).

${ }^{7}$ Using the consumer price indices at http://www.bls.gov/data/inflation_calculator.htm for the US and at https://www.destatis.de/DE/ZahlenFakten/GesamtwirtschaftUmwelt/Preise/Preise.html for Germany.

${ }^{8}$ In order to test for the role of small cells for the results of our analysis, we run robustness checks excluding household types with few observations (below 10 and below 30).

${ }^{9}$ The word 'childless' is used here as a shorthand to mean households that do not contain any resident children. It should not be taken in a literal sense.

${ }^{10}$ Incomes were converted to euros for the 1990s period in Germany.

11 These results were unaffected by the exclusion of small cells.

12 To check the robustness of our results, we ran the same analyses using a different measure from the family of generalized entropy indexes, namely half the squared coefficient of variation (GE index with coefficient $=2$ ). We obtained the same findings as with the Theil index (GE index with coefficient $=1$ ). These results are available from the first author on request.

${ }^{13}$ And when we changed both the within-group Theil and the mean incomes of household types to their 2000s values (not reported here), all of the income inequality growth observed in the US was accounted for. 
14 Robustness checks indicated that the counterfactual analysis is in some cases sensitive to excluding rare household types below 30 observations but not to excluding those with less than 10 observations. This only applies to the German data. The distribution of resources in some of the more uncommon household groups, such as those where women have more market power than their male partners, are likely to contribute to these effects. The results are available from the first author on request.

\section{Literature}

Aisenbrey, S., Evertsson, M. and Grunow, D. (2009). Is there a career penalty for mothers' time out? A comparison of Germany, Sweden and the United States. Social Forces, 88(2): 573-605.

Altonji, J. G., Bharadwaji, P. and Lange, F. (2012). Changes in the Characteristics of American Youth: Implications for Adult Outcomes, Journal of Labor Economics, 30(4): 783828.

Atkinson, A.B. (2003). Income Inequality in OECD Countries: Data and Explanations. CESifo Economic Studies 49: 479-513.

Bennett, F. (2013). Researching Within-Household Distribution: Overview, Developments, Debates, and Methodological Challenges. Journal of Marriage and Family, 75(3), 582-597. Blau, F. D., \& Kahn, L. M. (2013). Female Labor Supply: Why Is the United States Falling Behind? The American Economic Review, 103(3): 251-256.

Bradley, D., Huber, E., Moller, S., Nielsen, F., Stephens, J.D. (2003). Distribution and Redistribution in Postindustrial Democracies. World Politics 55: 193-228.

Breen, R., Andersen, S. (2012). Educational Assortative Mating and Income Inequality in Denmark. Demography, 49: 867-887.

Breen, R. and Chung, I. (2015). Income Inequality and Education. Sociological Science, 2: 454-77.

Breen, R., Salazar, L. (2011). Educational Assortative Mating and Earnings Inequality in the United States. American Journal of Sociology 117: 808-843.

Burtless, G. (1999). Effects of growing wage disparities and changing family composition on the U.S. income distribution. European Economic Review 43: 853-865. 
Cancian, M., Reed, D. (1998). Assessing the Effects of Wives’ Earnings on Family Income Inequality. Review of Economics and Statistics 80: 73-79.

Chandler, J., M. Williams, Maconachie, M., Collett, T., and Dodgeon, B. (2004). Living Alone: Its Place in Household Formation and Change. Sociological Research Online 9(3):114.

Cherlin, A. J. (2010). Demographic Trends in the United States: A Review of Research in the 2000s. Journal of Marriage and Family, 72: 403-419.

Giddings, L., Dingeldey, I., \& Ulbricht, S. (2004). The commodification of lone mothers' labor: A comparison of US and German policies. Feminist Economics, 10(2): 115-142.

Gornick, J.C., Jäntti, M. (2013). Introduction, in: Income Inequality - Economic Disparities and the Middle Class in Affluent Countries, Studies in Social Inequality. Stanford University Press, Stanford, California, pp. 1-47.

Harkness, S. (2013). Women's Employment and Household Income Inequality, in: Income Inequality - Economic Disparities and the Middle Class in Affluent Countries, Studies in Social Inequality. Stanford University Press, Stanford, California, pp. 207-233.

Jalovaara, M., and Fasang, A. (2017). From never partnered to serial cohabitors: Union trajectories to childlessness. Demographic Research, 36, 1703-1720.

Jamieson, L., and R. Simpson (2013). Living Alone: Globalization, Identity and Belonging. Basingstoke: Palgrave Macmillan.

Jäntti, M. (1997). Inequality in Five Countries in the 1980s: The Role of Demographic Shifts, Markets and Government Policies. Economica, 64: 415-440.

Kollmeyer, C. (2013). Family Structure, Female Employment, and National Income Inequality: A Cross-National Study of 16 Western Countries. European Sociological Review 29: 816-827.

LIS (2013). Luxembourg Income Study Database (LIS) www.lisdatacenter.org (multiple countries; 1980-2010), Accessed 5 June 2016.

Maldonado, L. C., \& Nieuwenhuis, R. (2015). Family policies and single parent poverty in 18 OECD countries, 1978-2008. Community, Work \& Family, 18(4), 395-415.

Mandel, H., \& Semyonov, M. (2014). Gender pay gap and employment sector: Sources of earnings disparities in the United States, 1970-2010. Demography, 51(5), 1597-1618. 
Martin, M. A. (2006). Family structure and income inequality in families with children, 1976 to 2000. Demography, 43(3): 421-445.

McCall, L., and Percheski, C. (2010). Income inequality: New trends and research directions. Annual Review of Sociology, 36, 329-347.

McGinnity, F., \& McManus, P. (2007). Paying the price for reconciling work and family life: Comparing the wage penalty for women's part-time work in Britain, Germany and the United States. Journal of Comparative Policy Analysis, 9(2), 115-134.

McLanahan, S. (2004). Diverging destinies: How children are faring under the second demographic transition. Demography, 41, 607-627.

McLanahan, S., Percheski, C. (2008). Family Structure and the Reproduction of Inequalities. Annual Review of Sociology, 34: 257-276.

Nieuwenhuis, R. and L. C. Maldonado (2018). “Single-Parent Families and In-Work Poverty”. In: Handbook of Research on In-Work Poverty. Ed. by H. Lohmann and I. Marx. Cheltenham: Edward Elgar.

Nieuwenhuis, R., Van der Kolk, H., and Need, A. (2017). Women’s earnings and household inequality in OECD countries, 1973-2013. Acta Sociologica, 60(1), 3-20.

OECD (2011). Divided We Stand Why Inequality Keeps Rising. Organization for Economic Cooperation \& Development Brookings Institution Press, Washington.

OECD (2017) Gender Wage Gap, Online-Resource: https://data.oecd.org/earnwage/genderwage-gap.htm, Accessed 15 September 2017.

Oesch, D. (2010). What explains high unemployment among low-skilled workers? Evidence from 21 OECD countries. European Journal of Industrial Relations, 16(1), 39-55.

Pasqua, S. (2008). Wives’ Work and Income Distribution in European Countries. European Journal of Comparative Economics, 5: 197-226.

Peichl, A., Pestel, N., Schneider, H. (2009). Demografie und Ungleichheit: der Einfluss von Veränderungen der Haushaltsstruktur auf die Einkommensverteilung in Deutschland. IZA Discussion Papers No. 4197.

Quintano, C. and D'Agostino, A. (2006), Studying Inequality in Income Distribution of Single-Person Households In Four Developed Countries. Review of Income and Wealth, 52: $525-546$. 
Reichman, N. E., Teitler, J. O., Garfinkel, I., \& McLanahan, S. S. (2001). Fragile families: Sample and design. Children and Youth Services Review, 23(4-5), 303-326.

Ronald, R. (2017). The Remarkable Rise and Particular Context of Younger One-Person Households in Seoul and Tokyo. City \& Community, 16(1), 25-46.

Sacher, M. (2005). Erwerbsstruktur und Alterssicherung-Entwicklungslinien des deutschen Arbeitsmarktes seit den 1980er Jahren. Wirtschaft und Statistik, 5(2005): 479-495.

Schröder, M., Siegers, R., \& Spieß, C. K. (2013). " Familien in Deutschland"-FiD: Enhancing research on families in Germany (No. 556). SOEPpapers on Multidisciplinary Panel Data Research, DIW Berlin, Germany.

Schwartz, C.R. (2010). Earnings Inequality and the Changing Association between Spouses' Earnings. American Journal of Sociology 115: 1524-1557.

Spitzenpfeil, M., Andreß, H.-J. (2014). Ist der Anstieg der westdeutschen

Einkommensungleichheit auf die Zunahme bildungshomogener Partnerschaften zurückführbar? Kölner Zeitschrift für Soziologie und Sozialpsychologie, 66: 575-601.

Teachman, J. D., Tedrow, L. M., \& Crowder, K. D. (2000). The changing demography of America's families. Journal of Marriage and Family, 62(4), 1234-1246.

Western, B., Bloome, D., Percheski, C. (2008). Inequality Among American Families With Children, 1975 to 2005, American Journal of Sociology, 73: 903-920.

White, L. and Rogers, S.J. (2000). Economic circumstances and family outcomes: A review of the 1990s. Journal of Marriage and Family, 62(4): 1035-1051.

Wolcott, E. L. (2017). Employment Inequality: Why Do the Low-Skilled Work Less Now? Working Paper, University of California, San Diego. 
Fig 1 Proportions of households by education (women's attainment levels grouped by men's)
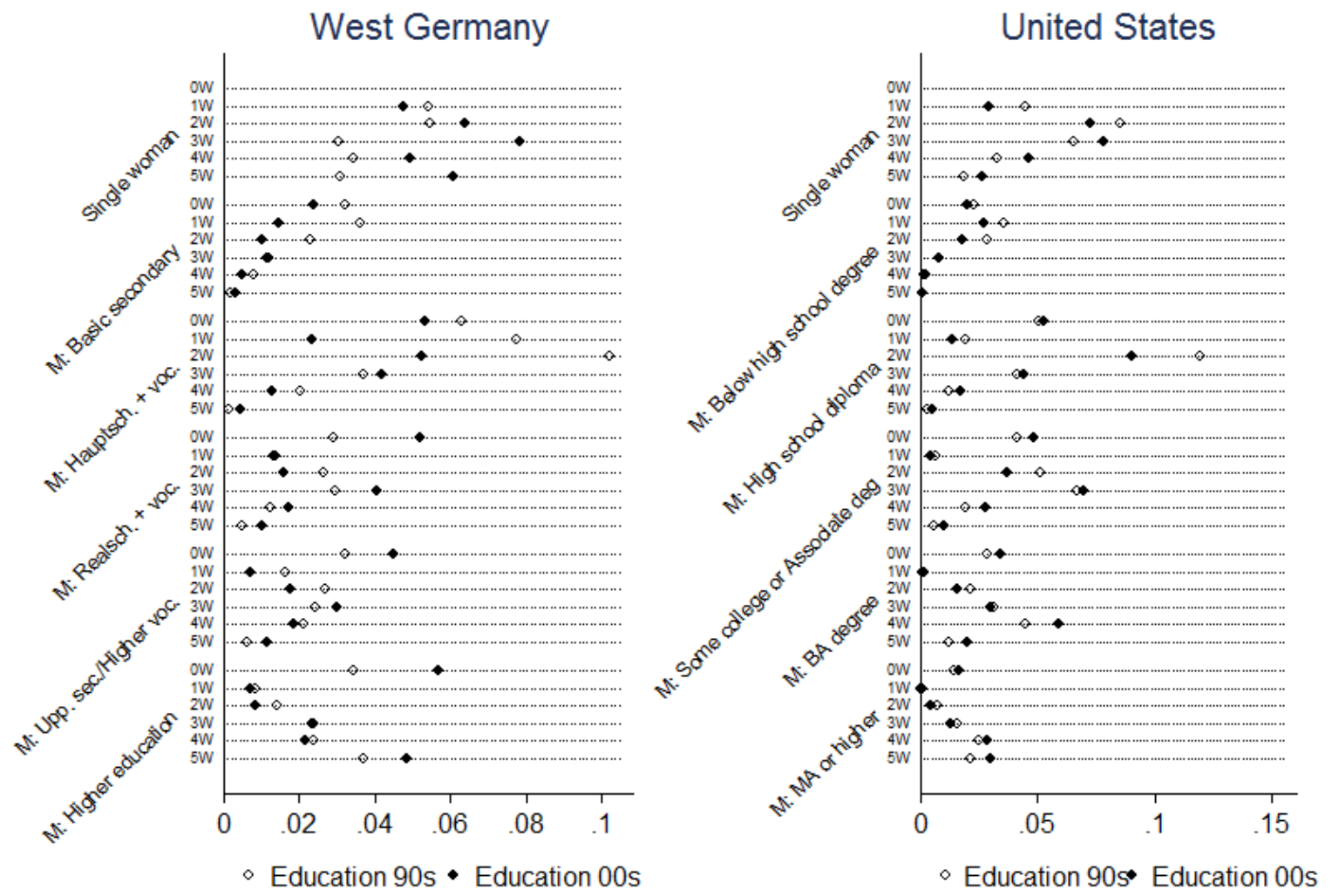

Notes: Women’s (W) educational attainment categories correspond to men’s (M); West Germany: 0: Absent, 1: Basic secondary, 2: Secondary (Hauptschule) plus vocational training; 3: Secondary (Realschule) plus vocational training; 4: Upper secondary or higher vocational qualification, 5: Higher education; US: 0: Absent, 1: Below high school degree, 2: High school diploma; 3: Some college or associate degree; 4: BA degree, 5: MA degree or higher 
Fig 2 Percentage point changes of men in employment by their education level between 1990s and 2000s

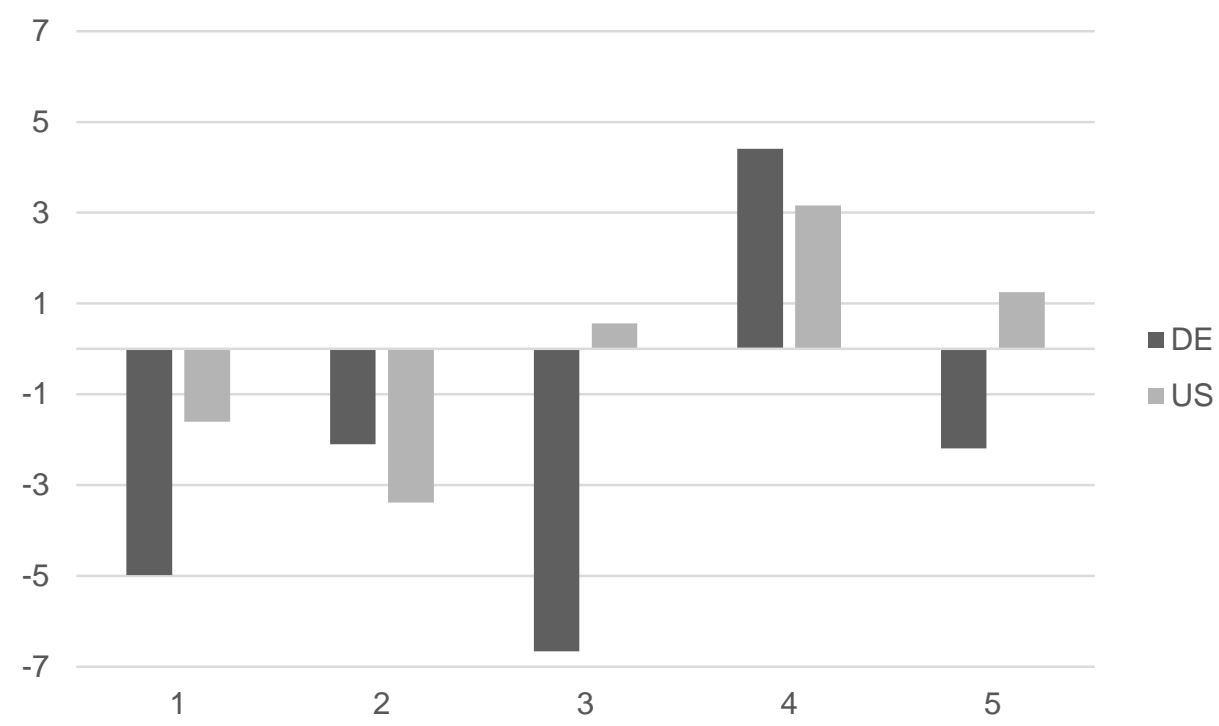

Notes: LIS data DE: 1989/94 and 2004/07 US: 1991/94 and 2004/07; weighted at household level. Educational attainment categories: DE: 1: Basic secondary, 2: Secondary (Hauptschule) plus vocational training; 3: Secondary (Realschule) plus vocational training; 4: Upper secondary or higher vocational qualification, 5: Higher education; US: 1: Below high school degree, 2: High school diploma; 3: Some college or associate degree; 4: BA degree, 5: MA degree or higher. 
Tab 1 Distribution of household compositions in West Germany and the US

\begin{tabular}{lrr|rr} 
& \multicolumn{2}{c|}{ West Germany } & \multicolumn{2}{c}{ United States } \\
\hline Share of household category (\%) & $\mathbf{1 9 8 9 / 9 4}$ & $\mathbf{2 0 0 4 / 0 7}$ & $\mathbf{1 9 9 1 / 9 4}$ & \multicolumn{1}{c}{$\mathbf{2 0 0 4 / 0 7}$} \\
\hline Households headed by a single person & 34.37 & 45.05 & 28.97 & 31.57 \\
Households headed by a single parent & 5.15 & 7.98 & 11.17 & 10.58 \\
Couple households without children & 31.25 & 23.36 & 24.60 & 25.82 \\
Couple households with children & 29.23 & 23.60 & 35.26 & 31.85
\end{tabular}

Notes: LIS data, DE: 1989, 1994, 2004, 2007; US: 1991, 1994, 2004, 2007; weighted at household level. 
Tab 2 Counterfactual analysis: Theil index and its components, West Germany

\begin{tabular}{lcrrrr} 
& Theil & $\begin{array}{c}\text { \% } \\
\text { Change }\end{array}$ & Between & Within \\
\hline 1990s observed & 0.1279 & & 0.0424 & 0.0856 \\
2000s observed & 0.1436 & 11 & 0.0450 & 0.0987
\end{tabular}

A. Basic counterfactuals (changing 1 component to 2000s value)

Change within-group Theil $\mathrm{Tj}$

0.1270

$-1 \quad 0.0423$

0.0847

Change mean incomes

0.1259

$-2$

0.0426

0.0833

Change hh distribution pj

$\begin{array}{llll}0.1558 & 22 & 0.0555 & 0.1002\end{array}$

B. Decomposing the distribution of household types (pj)

Change marginal distribution of education

$\begin{array}{llll}0.1422 & 11 & 0.0458 & 0.0964\end{array}$

Change marginal distribution of employment

$\begin{array}{llll}0.1399 & 9 & 0.0445 & 0.0954\end{array}$

Change marginal distribution of children

$\begin{array}{llll}0.1296 & 1 & 0.0433 & 0.0862\end{array}$

Change marginal distribution of education and empl

$0.1504 \quad 18$

0.0514

0.0990

C. Decomposing the distribution of household types (pj) by gender

Change marginal distribution of women's empl \& educ

0.1293

1

0.0439

0.0855

Change marginal distribution of men's empl \& educ

0.1446

13

$0.0478 \quad 0.0968$

Change marginal distribution of women's educ only

0.1306

$0.0447 \quad 0.0858$

Change marginal distribution of men's educ only

0.1355

0.0456

0.0898

Change marginal distribution of women's empl only

0.1283

$0.0425 \quad 0.0858$

Change marginal distribution of men's empl only

0.1337

5

$0.0438 \quad 0.0899$

D. Decomposing the distribution of household types (pj), single household characteristics

Change distribution of single, non-employed women

0.1363

7

$0.0445 \quad 0.0918$

Change distribution of single, employed women

0.1286

1

$0.0415 \quad 0.0870$ 
Tab 3 Counterfactual analysis: Theil index and its components, United States

\begin{tabular}{|c|c|c|c|c|}
\hline & & $\%$ & & \\
\hline & Theil & Change & Between & Within \\
\hline 1990s observed & 0.2112 & & 0.0786 & 0.1326 \\
\hline 2000s observed & 0.2306 & 9 & 0.0812 & 0.1494 \\
\hline
\end{tabular}

A. Basic counterfactuals (changing 1 component to 2000s value)

Change within-group Theil

Change mean incomes

Change hh distribution pj

$\begin{array}{lccc}0.2275 & 8 & 0.0786 & 0.1490 \\ 0.2171 & 3 & 0.0868 & 0.1303 \\ 0.2088 & -1 & 0.0736 & 0.1352\end{array}$

$\begin{array}{llll}0.2079 & -2 & 0.0748 & 0.1331\end{array}$

$\begin{array}{llll}0.2109 & 0 & 0.0777 & 0.1332\end{array}$

$\begin{array}{llll}0.2122 & 0 & 0.0780 & 0.1342\end{array}$

$\begin{array}{llll}0.2081 & -1 & 0.0745 & 0.1336\end{array}$

Change marginal distribution of education and empl

C. Decomposing the distribution of household types (pj) by gender

Change marginal distribution of women's empl \& educ

0.2089

$-1$

0.0760

0.1329

Change marginal distribution of men's empl \& educ

0.2126

0.0787

0.1339

Change marginal distribution of women's educ only

0.2308

0.0988

0.1319

Change marginal distribution of men's educ only

0.2178

0.0851

0.1326

Change marginal distribution of women's empl only

0.2192

0.0872

0.1319

Change marginal distribution of men's empl only

0.2371

12

0.1045

0.1326

D. Decomposing the distribution of household types (pj), single household characteristic

Change distribution of single, non-employed women

$\begin{array}{llll}0.2081 & -1 & 0.0733 & 0.1348 \\ 0.2103 & 0 & 0.0774 & 0.1329\end{array}$

Change distribution of single, employed women

(1)

